\title{
VALUING THE WILD, REMOTE AND BEAUTIFUL: USING PUBLIC PARTICIPATION GIS TO INFORM TOURISM PLANNING IN THE KIMBERLEY, WESTERN AUSTRALIA
}

\author{
J. STRICKLAND-MUNRO ${ }^{1}$, H. KOBRYN ${ }^{1}$, S.A. MOORE ${ }^{1} \&$ G. BROWN ${ }^{2}$ \\ ${ }^{1}$ Murdoch University, Australia. \\ ${ }^{2}$ University of Queensland, Australia.
}

\begin{abstract}
The remote Kimberley region in Western Australia presents a unique nature-based tourism destination. One of the world's last wildernesses, the Kimberley is one of the least-impacted marine environments in the world. Tourism in the region is growing rapidly, driven by stunning natural landscapes, unparalleled nature-based experiences and a vibrant indigenous culture. Despite this, there has been virtually no research into how stakeholders value the Kimberley and spatially explicit investigations are lacking. State marine protected area planning, currently in a formative stage in the region, requires such spatially explicit social data to complement existing biophysical information. This paper reports on findings from a Public Participation GIS survey with 206 stakeholders undertaken in 2015 as part of a broader research project into socio-cultural values and management preferences for the Kimberley coast. Stakeholders' spatially linked values were collected via an internet-based mapping survey for the purpose of supporting future planning and management in the region. Stakeholders mapped over 4,100 value locations, with values relating to scenery/aesthetics, recreational fishing, Aboriginal culture and naturebased tourism being most prominent. Analysis identified a clear spatial clustering of values across the region with a number of value 'hotspots' evident. Tourism planners and managers can analyse these hotspots to identify areas of potential congruence and conflict, thus assisting in retaining the qualities of the region that support ongoing tourism. By generating spatially explicit information on stakeholder values and areas of importance, this research makes an important contribution to tourism planning and management in the Kimberley.
\end{abstract}

Keywords: Kimberley, marine spatial planning, PPGIS social values.

\section{INTRODUCTION}

The wild, remote and beautiful Kimberley region dominates Australia's vast north-west. The Kimberley is a renowned nature-based tourism destination, offering stunning scenery and natural landscapes, a rich historical and contemporary Indigenous culture and unparalleled nature tourism experiences. Touted as one of the globe's few remaining wilderness areas, the region also boasts a comparatively pristine and untouched marine environment [1]. The Kimberley's many drawcards and environmental significance underpin an ongoing trend towards increasing visitor numbers in the region [2], as well as moves by policy makers to enact formal protection for the region's unique ecological and social character.

Seeking to retain the region's environmental character, in 2011 the West Australian Government introduced the Kimberley Science and Conservation Strategy [3]. The strategy committed to implementing a system of marine protected areas (MPAs) along the Kimberley coast, located at Eighty Mile Beach, Roebuck Bay (proposed), Lalang-garram/Camden Sound and North Kimberley (proposed). One other MPA has subsequently been established

This paper is part of the Proceedings of the $7^{\text {th }}$ International Conference on Sustainable Tourism (Sustainable Tourism 2016)

www.witconferences.com 
at Horizontal Falls (Fig. 1). The strategy further sought to foster enhanced scientific investigation in this under-researched region.

Despite increasing visitation and acknowledged environmental qualities, there has been virtually no research into how stakeholders value the Kimberley including a lack of spatially explicit investigations which are particularly important for planning and policy development. State MPA planning, currently in a formative stage in the region, requires such spatially explicit social data to complement existing biophysical information. This paper reports on research into stakeholder values for the Kimberley coast and marine environment, with this social data being made spatially explicit through the use of public participation GIS (PPGIS) technologies.

PPGIS is an accepted method for documenting spatially explicit social data in a manner that can readily inform planning processes. Used by natural resource managers across the globe and in a range of environment types and tenures, PPGIS data is applicable to both smaller scale conservation and protected area planning [5-7] and broader scale tourism and development planning $[8,9]$. PPGIS typically involves respondents placing markers representing values, ecosystem services or management preferences onto hard copy or online maps, with the resultant spatially explicit data assisting managers to: identify potential landuse conflict; assess the compatibility of land uses (e.g. MPA zoning) with landscape values; and provide public input to managing public lands (and waters) [8].

\section{METHODS}

\subsection{The Kimberley}

Western Australia's Kimberley region is a vast, remote and sparsely inhabited landscape. At $423,500 \mathrm{~km}^{2}$, the region is three times the size of England, with a population of 34,794 people, approximately $40 \%$ of whom are Indigenous [10]. The majority of Kimberley residents reside in the tourist nodes and service centres of Broome, Derby and Kununurra. Its highly crenulated coastline extends 7,331 km at MHW, excluding islands, and 13,296 $\mathrm{km}$ at LWM (including islands). The region has more than 1,700 islands [4] although access to these, as well as to the majority of the coastline itself, is very limited. Economic activities associated with the Kimberley coast and marine environment include tourism, commercial fishing, pearling and other aquaculture (e.g. barramundi farming), oil and gas extraction, iron ore mining, and pastoralism.

\subsection{PPGIS study}

The study used an online PPGIS approach to document stakeholder values for the Kimberley coast, focusing on an area stretching from the Western Australian State border down to the southern end of Eighty Mile Beach (Fig. 1). Upon entering the survey website, respondents were greeted with a welcome screen and required to enter a unique access code, later used to link individuals to their responses. The survey had three components: (1) pre-mapping sociodemographic questions (including age, gender, residence and education); (2) value and preference mapping; and (3) post-mapping 'stakeholder profiling' questions (e.g. environmental worldviews, stakeholder group affiliation).

The mapping interface consisted of Google ${ }^{\circledR}$ maps and images of the entire Kimberley region, with the coastal and marine study area boundary clearly marked in contrasting colour. Additional layers depicting i) marine and terrestrial protected area boundaries and ii) key 


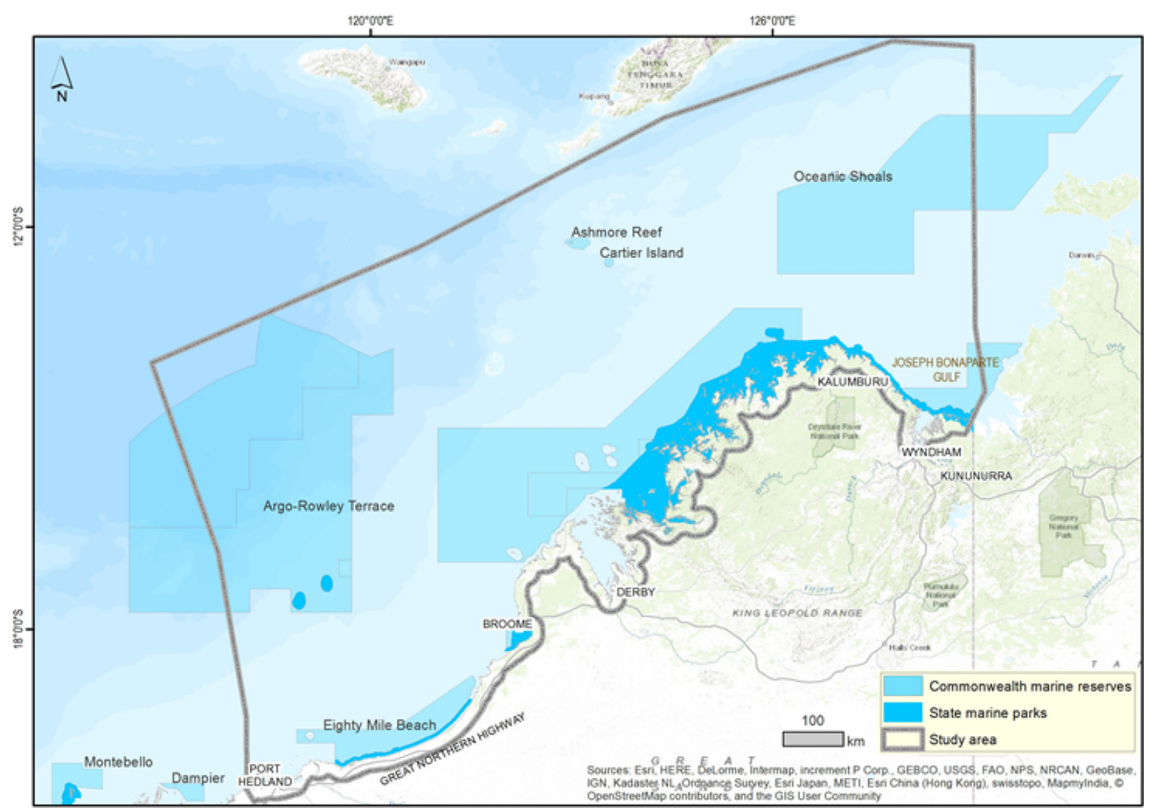

Figure 1: Kimberley marine parks (current and proposed) [4], Dept. Parks and Wildlife Sept 2016. Grey line depicts the study area boundary.

coastal access points, Aboriginal communities and tourist nodes were added to this base. Respondents could zoom in and out to orientate themselves, although a $10 \mathrm{~km}$ minimum mapping resolution (i.e., $1 \mathrm{~cm}$ on the Google ${ }^{\circledR}$ map $=10 \mathrm{~km}$ on the ground) was enforced. This meant that respondents could not undertake mapping until they had zoomed in to a sufficient scale $(\leq 10 \mathrm{~km})$. This scale represented a compromise between mapping accuracy and the vast scale of the study area.

Respondents were asked to place markers representing pre-defined values and preferences (Fig. 2) on the map interface; this paper is concerned with values only. The value set was derived through an earlier interview-based phase of research [11] and accorded with those used in multiple PPGIS studies, pioneered by Brown and Reed [12]. Definitions for each value were available by hovering over the relevant marker. Respondents could place as many markers as they like, with a minimum of one marker needing to be placed before progression through to post-mapping questions.

\subsubsection{Sampling design}

Respondents were sourced from both the general public and an online panel maintained by a commercial research company. This sampling design was intended to gather data from stakeholders both with (general public) and without (panel members) an identifiable interest in, or knowledge of, the Kimberley. This paper reports on findings from panel respondents only. Despite assumptions of no identifiable interest, panel members were likely however to hold some prior knowledge of the region, given its political prominence and tourism significance. A sample representative of Western Australian residents aged 18 years and over was sought. Panel members were remunerated for their participation. 


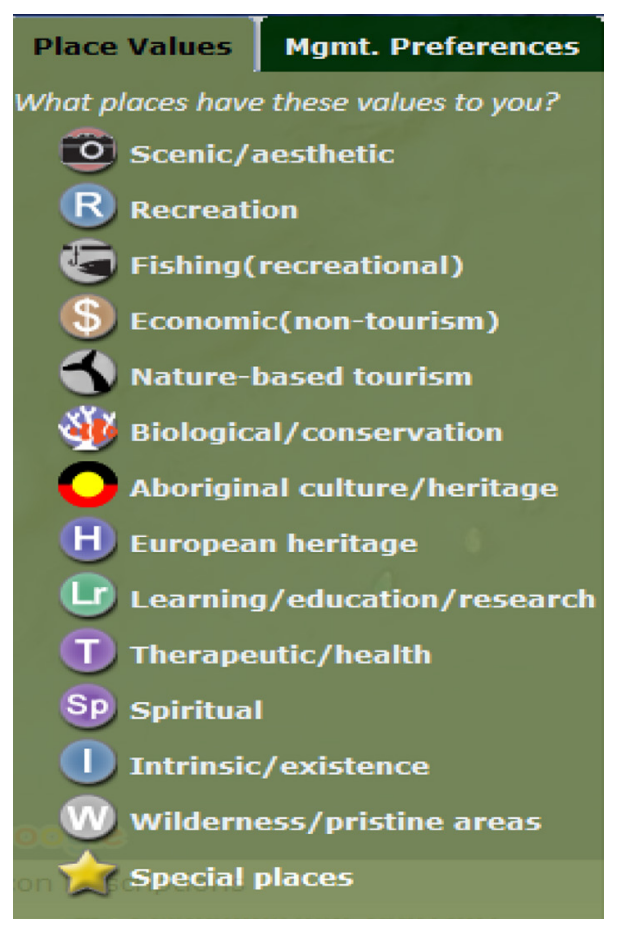

Figure 2: PPGIS value choice set.

\subsubsection{Data analysis}

Three phases of data analysis were undertaken. 1. Survey data were exported into Microsoft Access database and basic summary analyses were performed. 2. Value marker data were plotted using geographic information systems (GIS) on separate maps representing each of the value categories. This provided a geographic overview of value extent. 3. These basic geographic data were used to create point density maps indicating areas of greatest relative value intensity ('hotspots'). Creation of the point density maps was underpinned by the understanding that aggregations of special place maps (i.e. hotspot maps) exhibit a degree of collective, spatial consistency [cf. 12]. Point density maps are displayed here using a colour scale with a histogram stretch of 2.5 standard deviations from the mean.

\section{RESULTS}

A total of 206 respondents completed the PPGIS survey through the online panel. Response numbers vary in the results presented below as pre- and post-mapping questions were optional. Relevant sample sizes are indicated as appropriate.

\subsection{Respondent profile}

Table 1 presents respondent socio-demographics in comparison with Western Australia census data. It is evident that i) respondents were predominantly female; ii) a relatively even range of age groups was represented, with respondent numbers for the 24 to 74 years old age groups exceeding those of the broader Western Australian population; and iii) PPGIS 
respondents are more proportionally likely to hold undergraduate/Bachelor or postgraduate degrees than the Western Australian population (Table 1).

Over $82 \%$ of respondents identified as Australian citizens. Nineteen percent did specify citizenship, and one respondent was an Indonesian citizen. The vast majority of respondents $(97.5 \%)$ were not current or previous Kimberley residents. Two respondents (1\%) identified as previous Kimberley residents. Almost half of the respondents (43\%) reported an 'average' level of knowledge about the Kimberley coast and marine environment, followed by those reporting 'poor' (21\%) and 'below average (20\%) knowledge. Sixteen percent of respondents reported having 'good' or 'excellent' knowledge of the study area.

More than half of the respondents $(58.2 \%)$ had visited the study area previously. Most (29.6\%) had visited between 2 and 5 times while $10.7 \%$ had visited in excess of 6 times (range 6-50 visits). Almost $42 \%$ had never visited the region. Respondents were representative of a broad range of stakeholder groups. The majority of respondents (85.4\%) identified their main relationship with the Kimberley as 'visitor'. The next most common stakeholder affiliation was the free-choice option 'other' (12.4\%), followed by Government (8.7\%) and oil/gas industry (5.3\%). As respondents could choose more than one affiliation figures sum to more than $100 \%$.

In regards to the future of the Kimberley coast and marine environment, respondents were most concerned about 'protecting biological and ecological features found in the region' $(49.5 \%, \mathrm{~N}=219)$. This was followed by concerns regarding 'ensuring marine/coastal plans

Table 1: Respondent characteristics with comparison to Western Australia census [10].

\begin{tabular}{lcc}
\hline Socio-demographic $(\mathrm{N}=219)$ & PPGIS panel respondents & WA 2011 census \\
\hline Age (\%) & 6.8 & \\
$18-24$ & 22.7 & 9.7 \\
$25-34$ & 24.2 & 14.9 \\
$35-44$ & 16.8 & 14.5 \\
$45-54$ & 16 & 13.8 \\
$55-64$ & 13.5 & 11.3 \\
$65-74$ & 0 & 6.8 \\
$75-84$ & 0.1 & 3.9 \\
Unspecified & & - \\
Gender $(\%)$ & 37.5 & 50.3 \\
Male & 62.5 & 49.7 \\
Female & & \\
Highest level of education completed $(\%)$ & 0.5 & 4.0 \\
Primary & 17.8 & Data unavailable \\
Secondary & 14.9 & Data unavailable \\
Some tertiary & 32.2 & 15.2 \\
Undergraduate/Bachelor degree & 22.1 & 28.6 \\
Vocational/technical training & 12.5 & 2.9 \\
Postgraduate degree & & \\
\hline
\end{tabular}


are developed/ implemented/ supported' (13.5\%), 'ensuring the rights of Traditional Owners/ Aboriginal people in the region' (13.1\%) and 'maintaining and developing tourism opportunities' $(8.3 \%)$.

\subsection{Values mapping}

A total of 4,108 value markers were placed in the PPGIS survey. Figure 3 depicts the relative percentage of markers mapped for each value category. Scenic values dominated $(17.0 \%$ of all value markers placed), followed by recreational fishing (12.7\%), Aboriginal culture and heritage $(11.1 \%)$ and nature-based tourism $(11.1 \%)$. Together, these four values accounted for over $50 \%$ of all value markers placed. Special place, therapeutic and 'other' values recorded the least number of markers (Fig. 3). Figure 4 provides an overview of important localities as a preface to further discussion of values mapping.

Figures 5 and 6 depict point density maps for the eight most numerous value categories, moving from the value with the greatest percentage of markers placed (scenic) to the value with the least percentage of markers placed (economic).

The most important interpretation of Figs 5 and 6 is that no part of the Kimberley coast is free of value. The entire study area's coast and associated marine environment is represented by one or more of the value categories included in Figs 5 and 6. Beyond this generality, areas of value concentration (hotspots) are evident. Roebuck Bay (including the proposed Roebuck Bay MPA) and the Broome region feature as a hotspot for all eight value categories. This accords with Roebuck Bay's position as preferred playground for a range of pastimes including fishing, relaxation and other recreation pursuits. Typified by the striking visual contrasts and vistas that characterise the region; Roebuck Bay is also a Ramsar site notable for its seasonal flocks of migratory waterbirds as well as populations of rare or endangered marine animals. A number of tours operate in the Bay associated with water-based recreation, wildlife and Aboriginal culture.

Biological value was denoted across the majority of the coastline and displayed the greatest number of hotspots (6). In addition to Roebuck Bay, these were located along Eighty Mile

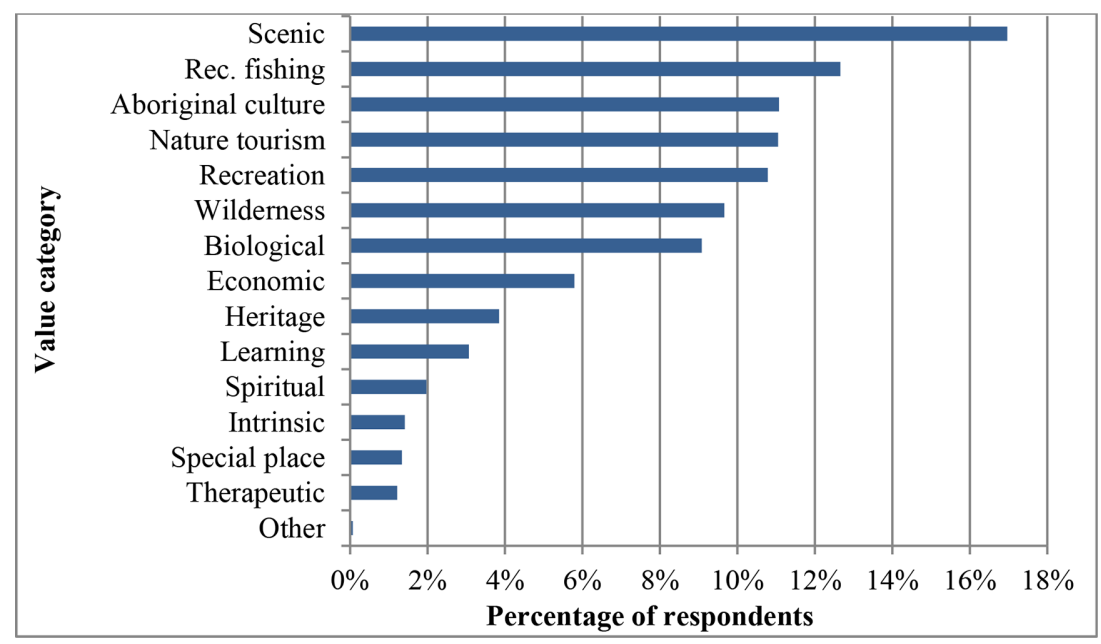

Figure 3: Relative percentage of markers mapped per value category. 


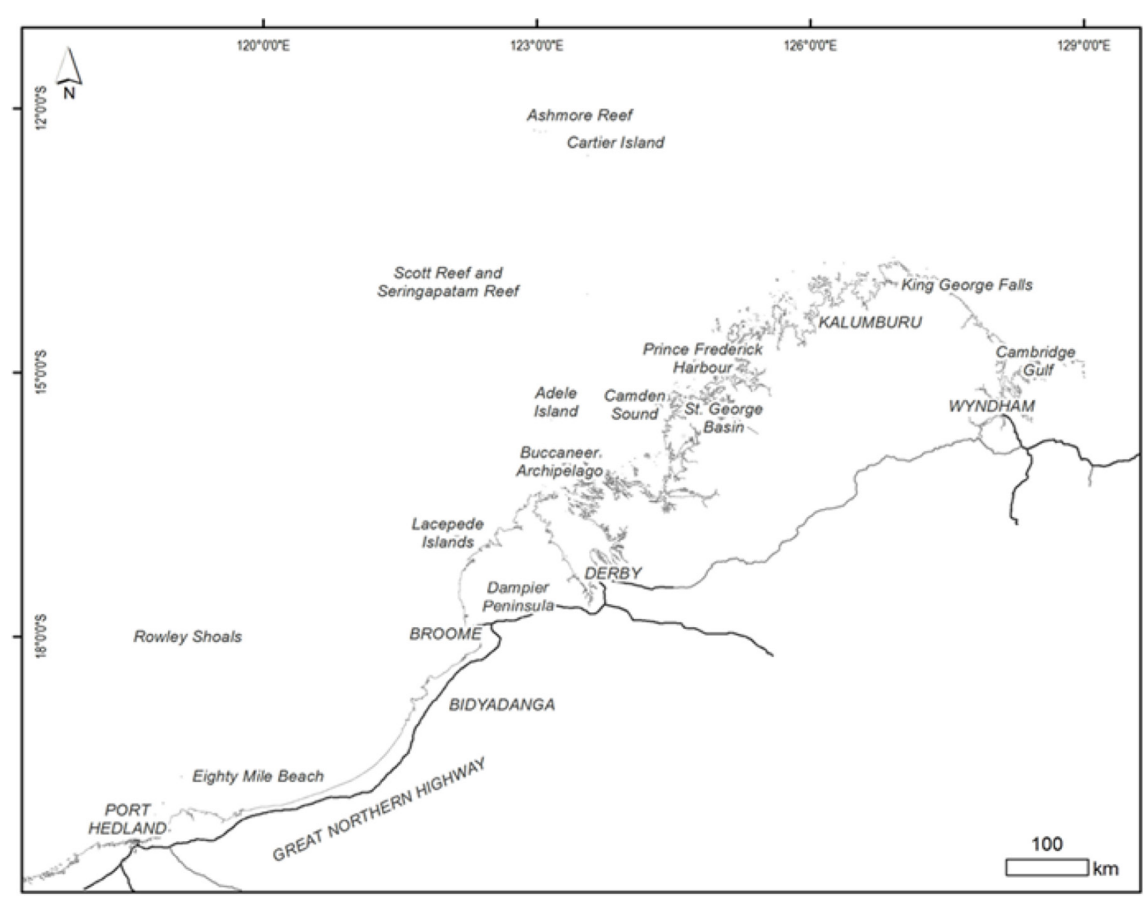

Figure 4: Location of key mapped areas for values.

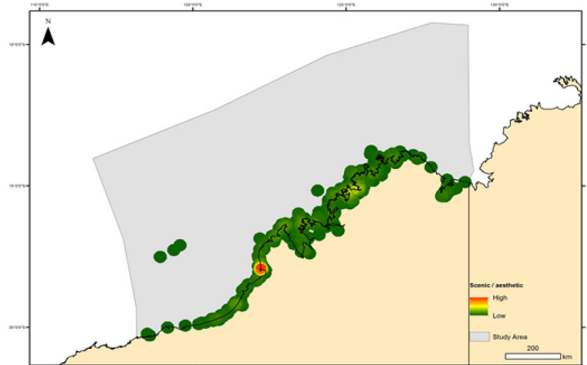

a

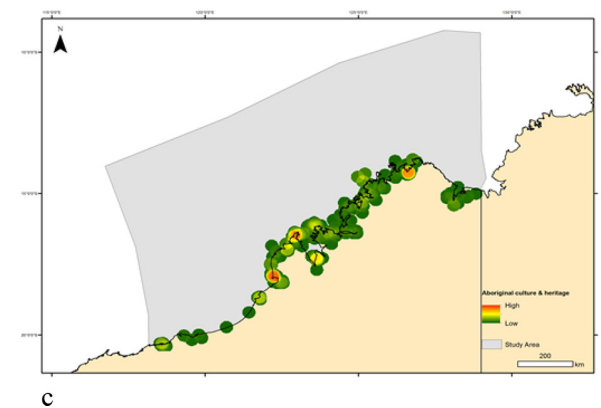

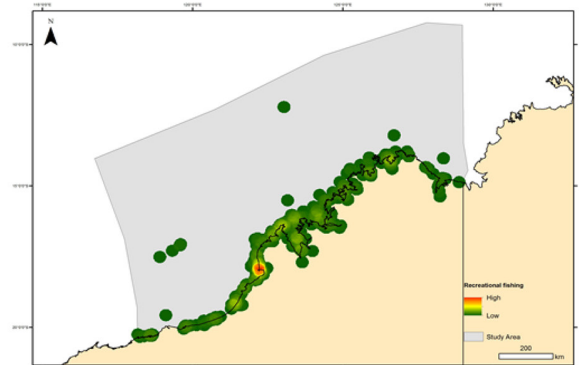

b

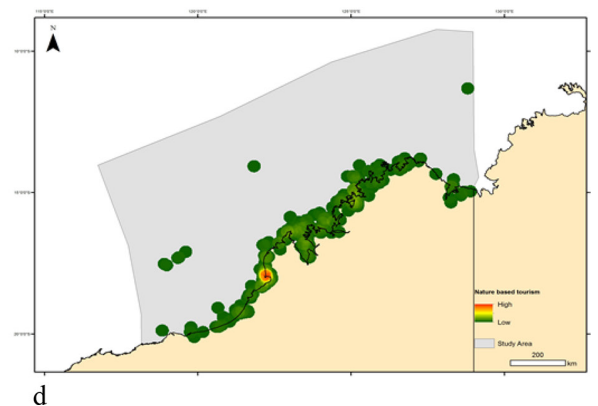

Figure 5: Point density maps for (a) scenic; (b) recreational fishing; (c) Aboriginal culture and heritage; and (d) nature-based tourism value. 

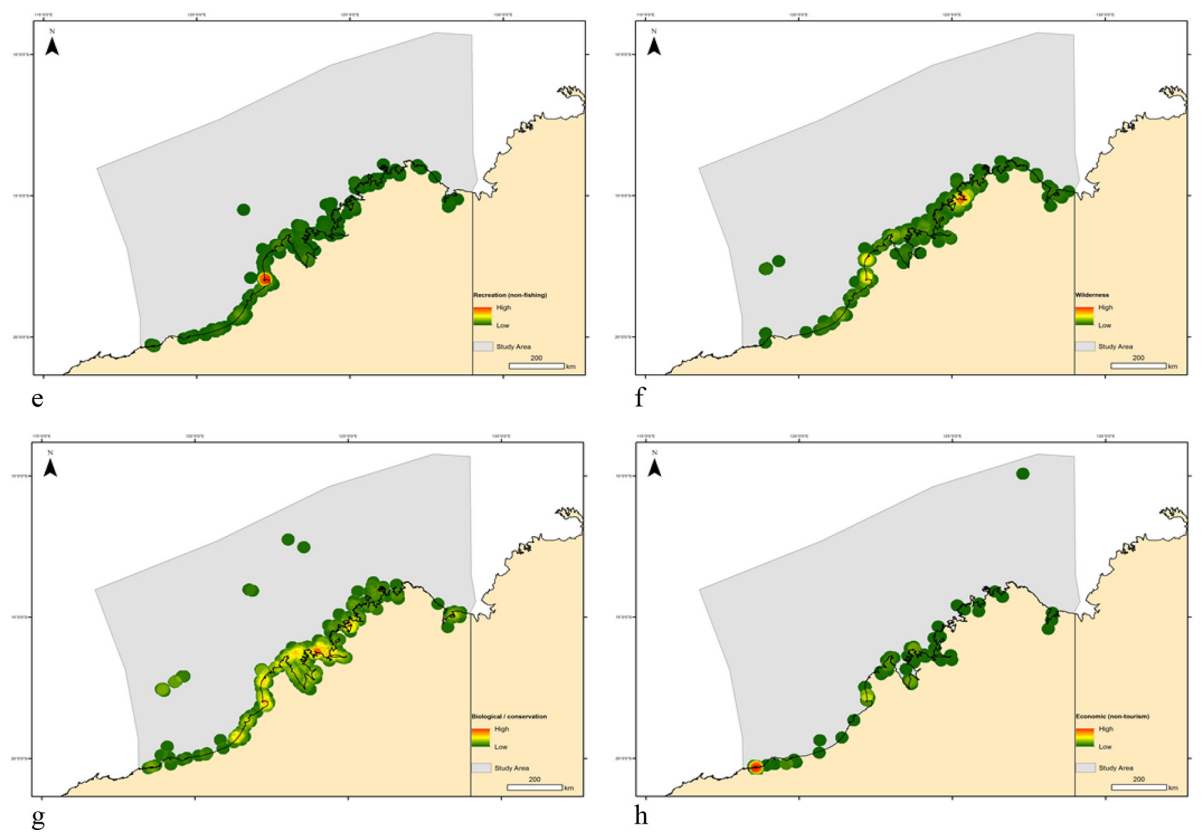

Figure 6: Point density maps for (e) recreation; (f) wilderness; (g) biological; and (h) economic value.

Beach, also a Ramsar site; Horizontal Falls MPA region; the western Dampier Peninsula; Buccaneer Archipelago; and St. George Basin. The large number of hotspots is unsurprising, given the Kimberley's ecological significance. Aboriginal culture and heritage recorded the next greatest number of hotspots (4). These centred on Roebuck Bay, the northern Dampier Peninsula, southern King George Sound/Derby region and Kalumburu. These hotspots may reflect the fact all four locations are key population centres for the Kimberley's Aboriginal population. The northern Dampier Peninsula in particular is renowned for (and heavily promoted as) offering opportunities for visitors to engage with Aboriginal culture, and boasts a number of award winning Aboriginal tourism ventures and accommodation options.

The majority of the coastline was attributed with wilderness value, with three distinct hotspots evident: Roebuck Bay, Prince Frederick Harbour and the western Dampier Peninsula. The inclusion of Roebuck Bay, a popular recreational area, as a wilderness hotspot is an interesting outcome, and again may reflect respondent familiarity with Roebuck Bay given its proximity to Broome, the tourism gateway to the Kimberley. Similarly, for those respondents generally unfamiliar with the region, the denoting of the western Dampier Peninsula as a wilderness hotspot was likely influenced by significant recent media coverage of the area. This publicity, relating to politically and socially controversial plans to establish a liquid natural gas processing plant, typically characterised the area as pristine. The final wilderness hotspot, Prince Frederick Harbour, is perhaps the 'truest' wilderness destination, in terms of remoteness, lack of accessibility and natural values. The Harbour, accessible only by expedition cruise vessel or light plane, is noted for its isolation and resultant pristine ecosystems. Economic value was more discrete in nature, with one hotspot located near Port Hedland, a major resource-industry town. A less-pronounced hotspot is evident in Roebuck Bay; this 
perhaps reflects cognisance of recent commercial fishing operations in the Bay and the presence of the Broome Port.

Nature-based tourism values were attributed to a large portion of the coastline, with a hotspot centred on the Broome area. This particular hotspot may reflect the area's easy accessibility and Broome's position as the Kimberley's main tourist hub. As such, those respondents who had previously visited the Kimberley would likely be familiar with the area, while those who had not visited would still most likely be aware of the area's tourism significance.

The social data gathered in this research provides important information to support future tourism development along the Kimberley coast. In particular, it identifies the Broome/Roebuck Bay area as critical for planning and management, with this area being a focal point for a broad range of values. Any future developments must remain cognisant of the area's high value and strive to retain and build upon the qualities that currently underpin stakeholder values. This will necessitate careful consideration of potentially competing values, for example the need to provide for recreation, fishing and tourism opportunities while simultaneously safeguarding the area's cultural significance, biological diversity and wilderness values.

\section{CONCLUSION}

This paper has reported on a PPGIS study undertaken to ascertain stakeholder values for the wild, remote and increasingly-visited Kimberley region of Western Australia. Using an internet-based PPGIS methodology, 206 online research panel respondents were asked to spatially indicate where they held certain values for the Kimberley coast and marine environment. Over 4,100 value locations were mapped, with the entire coastline being associated with some form of value. Values relating to scenery/aesthetics, recreational fishing, Aboriginal culture and nature-based tourism accounted for over 50\% of all values markers mapped. Value hotspots were evident at or close to: Eighty Mile Beach; Roebuck Bay; the western and northern Dampier Peninsula; Derby; Horizontal Falls MPA region; St. George Basin; Prince Frederick Harbour and Kalumburu.

These value-specific hotspots offer tourism and conservation planners and managers a readily-integrated dataset that can be used to support conservation and sustainable tourism development along the Kimberley coast. For instance, the dataset offers information that can assist in planning for MPA zoning and resource allocation, or to help guide siting for the installation of recreational facilities. Being guided by some knowledge of what stakeholders value, and where, reduces the potential for significant conflict and heightens the chance of achieving and maintaining stakeholder support. By generating spatially explicit information on stakeholder values and areas of importance, this research makes an important contribution to tourism planning and management the Kimberley.

\section{REFERENCES}

[1] Halpern, B.S., Walbridge, S., Selkoe, K.A., Kappel, C.V., Micheli, F., D’Agrosa, C., Bruno, J.F., Casey, K.S., Ebert C., Fox, H.E., Fujita, R., Heinemann, D., Lenihan, H.S., Madin, E.M.P., Perry, M.T., Selig, E.R., Spalding, M., Steneck, R. \& Watson, R., A global map of human impact on marine ecosystems. Science, 319(5865), pp. 948-952, 2008.

http://dx.doi.org/10.1126/science.1149345 
[2] Tourism Western Australia, Kimberley Development Commission Area: Overnight Visitor Fact Sheet. Year Ending December 2014, Government of Western Australia: Perth, 2015.

[3] Government of Western Australia, Kimberley Science and Conservation Strategy, Government of Western Australia: Perth, 2011.

[4] Geoscience Australia, Applying geoscience to Australia's most important challenges. Retrieved 23 September, 2015, available at http://www.ga.gov.au/

[5] Green, D.R., The role of Public Participatory Geographical Information Systems (PPGIS) in coastal decision-making processes: an example from Scotland, UK. Ocean \& Coastal Management, 53(12), pp. 816-821, 2010.

http://dx.doi.org/10.1016/j.ocecoaman.2010.10.021

[6] van Riper, C.J., Kyle, G.T., Sutton, S.G., Barnes, M. \& Sherrouse, B.C., Mapping outdoor recreationists' perceived social values for ecosystem services at Hinchinbrook Island National Park, Australia. Applied Geography, 35(1-2), pp. 164-173, 2012. http://dx.doi.org/10.1016/j.apgeog.2012.06.008

[7] Plieninger, T., Dijks, S., Oteros-Rozas, E. \& Bieling, C., Assessing, mapping, and quantifying cultural ecosystem services at community level. Land Use Policy, 33, pp. 118-129, 2013. http://dx.doi.org/10.1016/j.landusepol.2012.12.013

[8] Brown, G. \& Weber, D., Measuring change in place values using public participation GIS (PPGIS). Applied Geography, 34, pp. 316-324, 2012. http://dx.doi.org/10.1016/j.apgeog.2011.12.007

[9] Brown, G., Weber, D. \& de Bie, K., Assessing the value of public lands using public participation GIS (PPGIS) and social landscape metrics. Applied Geography, 53, pp. 77-89, 2014. http://dx.doi.org/10.1016/j.apgeog.2014.06.006

[10] Australian Bureau of Statistics. (2011). 2011 Census Data. Retrieved 27 August, 2015, availabel at http://www.censusdata.abs.gov.au

[11] Strickland-Munro, J., Moore, S., Kobryn, H. \& Palmer, D., Values and aspirations for coastal waters of the Kimberley: Social values and participatory mapping using interviews. Technical Report. Kimberley Marine Research Program Node of the Western Australian Marine Science Institution. Perth, Western Australia, Western Australian Marine Science Institution, 2015.

[12] Brown, G. \& Reed, P., Validation of a forest values typology for use in national forest planning. Forest Science, 46(2), pp. 240-247, 2000. 